\title{
Use of biochar as media for propagation of some difficult-to-root ornamental plants
}

\author{
Hannah-Vic Adzraku, Paul K. Tandoh*, Latifatu H. Zurei \\ Kwame Nkrumah University of Science and Technology, 233 Kumasi, Ghana
}

Received: 17 August 2017

Accepted: 11 September 2017

Published online: 30 December 2017

\begin{abstract}
A study was carried out at the Department of Horticulture, KNUST from 8th January, 2017 to 17th March, 2017 to determine the best propagating medium for Ixora coccinea and Ficus pumila. The design was a Complete Randomized Design with four treatments replicated three times. The treatments were; topsoil only, biochar only, mixture of topsoil and biochar (1:1) and mixture of topsoil and biochar $(2: 1)$. The study revealed that the treatment with the mixture of topsoil and biochar $(2: 1)$ was the best medium, in terms of physical and chemical properties and produced the highest number of leaves and rooted cuttings in Ficus pumila. Topsoil only had highest number of leaves and roots for Ixora coccinea. The biochar medium started rooting earlier for Ficus pumila at 2 weeks and recorded the highest number of leaves, while that of Ixora coccinea rooted at the fourth week towards the fifth week. The study concluded that mixture of topsoil and biochar $(2: 1)$ could be used for propagating difficult to root ornamental plants whiles Biochar only could also be used to propagate Ficus pumila.
\end{abstract}

Keywords: sequestration, Feedstock, propagules and sprouting

\section{Introduction}

An increased emphasis on sustainability and environmentally sound uses of natural resources have led to many innovative efforts to minimize carbon footprints and negative impact to the environment. Incorporating climate change mitigation strategies into routine practices is one such approach to promote sustainability. Current research findings reveal that application of biochar to soils improves soil quality and plant growth (Chan et al. 2009) and reduces emissions of greenhouse gases (GHGs) in particular nitrous oxide (Yanai et al. 2007, Van Zwieten et al. 2009). Biochar unlike fertilizers has extremely long life in soils due to its molecular structure. Biochar is chemically and biologically in a more stable form than the original carbon form. This means that in some cases it can remain stable in soil for hundreds to thousands of years. Biochar is under investigation as an approach to carbon sequestration with a high potential to reduce negative carbon dioxide emissions with the view to combating climate change (Lean 2008). It increases yield of crop production, very effective in adsorbing organic pollutants from waste water, improves soil tilth and water retention, reduces soil erosion, vulnerability to degradation, and to some extent reduce the need for fertilizer inputs (Reddy et al. 2014). Wide ranges of biomass sources have been used to make biochar, these include: woody materials, agricultural and food wastes (Ioannidou and Zabaniotou 2007), green wastes (Chan et al. 2007) animal manures (Chan et al., 2008) and wastes from the paper mill industry (Van Zwieten et al. 2010).

${ }^{*}$ Corresponding author: P. K. Tandoh

e-mail: paulusnow@gmail.com 
Some of the ornamental plants in Ghana are in high demand for landscape works, cut flowers, bouquets and wreaths making (Idun et al. 2011). Ficus pumila and Ixora coccinea are among the very economically important ornamental plants used widely in Ghanaian landscapes. These plants are known to have a low genetic and physiological capacity for adventitious root formation and therefore limit their commercial production. They are popularly called as "difficult-to-root" plants. In order to boost commercial production to meet high market demand, however, the difficult-to-root phenomenon should be overcomed. It is against this background that different soil amendments using biochar have to be studied to optimize the rooting of these ornamental plants. Additionally, since food wastes cannot be eliminated completely, converting them into a useful product would both reduce environmental damage and provide other benefits. Researchers are investigating the potential to replace peat and other commonly used nursery materials with more sustainable options (Dombrowky et al. 2013). Biochar is one material showing promise as a replacement for peat (Steiner and Harttung 2014), perlite (Northup 2013) and vermiculite (Dumroese et al. 2011). The opportunity to investigate the potential for plant propagation biochar, while simultaneously sequestering carbon at no additional cost to production nurseries, stands to alter the sustainability of current propagation practices (Caron and Rochefort 2013). However, there is dearth of knowledge on the specific biochar feed stock to be used as media for propagating difficult-to-root plants and therefore the objective of this study was to determine the effect of the biochar prepared from sugarcane feedstock in promoting rooting in Ixora coccinea and Ficus pumila.

\section{Materials and Methods}

\subsection{Experimental site}

The study took place at the Department of Horticulture, Faculty of Agriculture, Kwame Nkrumah University of Science and Technology (KNUST), Kumasi from December 2016 to February 2017. The site is in the semi-deciduous forest zone with an elevation of $186 \mathrm{~m}$ above sea level (ASL) and a bimodal rainfall distribution. The major rainy season is from late March to mid-July. There is a short dry spell from mid-July to mid-September followed by the minor rainy season from midSeptember to mid-November. The mean annual rainfall is $1500 \mathrm{~mm}$. The mean minimum and maximum temperatures are $21^{\circ} \mathrm{C}$ and $31^{\circ} \mathrm{C}$ respectively. The mean annual relative humidity is $95 \%$ in the morning and about $60 \%$ at noon. The soil at the experimental site is ferric Acrisol.

\subsection{Experimental design}

The experimental design used was a Complete Randomized Design (CRD) with 3 replications. Treatments used were; Topsoil only, Biochar only, mixture of topsoil and biochar (1:2), mixture of topsoil and biochar (2:1). The different media formulations were measured with a $15 \mathrm{~cm} \mathrm{x} 7 \mathrm{~cm}$ container half filled with each treatment. Media for Ixora coccinea were put in 4-inch diameter round plastic pot with 5 cuttings in each pot. The container for Ficus pumila was 8 inch diameter round plastic pot also holding 5 cuttings each.

\subsection{Source of stock plants and media}

Cuttings from stock plants of Ixora coccinea and Ficus pumila were taken from the Department of Horticulture, KNUST. The raw material used for the media formulations were sugarcane waste, which was collected at Ahomaso in Kumasi, and the topsoil obtained from the Department of Horticulture. 
H. V. Adzraku et al.

\subsection{Preparation of media and cuttings}

The sugarcane waste was dried on a concrete floor for 2 weeks under direct sunlight in an open space. These were turned over twice every day to ensure uniform drying, and covered every sundown with a black polyethene sheet to avoid getting wet in case it rained overnight. It was then charred in a small-scale biochar reactor (Plate 6), at a temperature of $250^{\circ} \mathrm{C}$. The lengths for each cutting of Ixora coccinea and Ficus pumila were $20 \mathrm{~cm}$ and $10 \mathrm{~cm}$ respectively, and each had 3-4 nodes. The cuttings were taken between 7: $10 \mathrm{am}$. Cuttings of Ixora coccinea and Ficus pumila had lower leaves stripped. None of the cuttings was treated with any rooting hormone.

\subsection{Experimental procedure}

The experiments were set-up in the lath house of the Department of Horticulture, KNUST. The layouts for each stock plant were a twelve plastic pot representing the number of treatment combinations. Perforated plastic containers were filled with equal volumes of each medium; topsoil and biochar and before the cuttings were inserted into the medium, the medium was moistened and allowed to settle. Transparent polythene sheets were used to cover all sides of the containers to create as suitable condition necessary for rooting of the cuttings. The perforations on the plastic pots were to drain off excess water from the media. Each media was firmed in the plastic pots so that it was able to hold the cuttings in place. A dibber was used to create the hole for the insertion of the cuttings. After inserting the cuttings in an upright form, the medium was pressed firm around the cuttings and then watered. Data were collected on the following parameters (i) Temperature and relative humidity of mediumtemperature for the different media were recorded between 9:00 am and 3:00 pm on each recorded date with a laser temperature reader (ThermoTrace Infrared Thermometer (Model 15030)-Delta TRAK, USA) whiles the humidity of the media containing the cuttings were also recorded using a temperaturehumidity reader (Micronta LCD Indoor/Outdoor Thermometer Hygrometer (Model 63-867)-InterTAN, UK) between 9:00 am and 3:00 pm on each recorded date. (ii) Days to sprouting-the number of days for the cuttings of Ixora coccinea and Ficus pumila to sprout were counted. (iii) Number of rooted cuttings-the number of cuttings that had successfully rooted were counted. (iv) Root length per cuttingThe root lengths were measured using a pair of dividers and ruler from the point of attachment of the roots to the distal end of the stem cuttings. This was done on two randomly selected roots and the average root length recorded. The root length measurement was taken for Ficus pumila and Ixora coccinea from 2 weeks and 4 weeks respectively, and every other week to the 10th week to the end of the experimental period. (v) Number of fully developed leaves per cutting-the number of fully developed leaves from the sprouts on the cuttings of Ixora coccinea and Ficus pumila were counted. Records were taken at 4 weeks after propagation (WAP) and subsequently on weekly basis till the experiments were terminated in the 10th week.

\subsection{Data Analysis}

Data collected were subjected to analysis of variance using Statistix version 9.0. The Least Significant Difference (LSD) was used for mean separation at a probability level set at $\mathrm{p}=0.05$.

\section{Results}

\subsection{Laboratory media analysis for the different media}

Biochar recorded significantly highest percentage of nitrogen and the least was recorded by the mixture of topsoil and biochar (2:1) (Tab.1). Significantly, high percentage was recorded for biochar in phosphorus content table and the least recorded similarly in the other media. Also, Biochar recorded 
H. V. Adzraku et al.

significantly high percentage of potassium content and the least recorded in topsoil which was similar to the mixture of topsoil and biochar (2:1). For pH, biochar was slightly basic with a value of (8.86) and topsoil slightly acidic recording (6.41).

Tab. 1 The media analysis of various media.

\begin{tabular}{lllll}
\hline Treatment & Nitrogen $\%$ & Phosphorus $\%$ & Potassium \% & $\mathrm{pH}$ \\
\hline Topsoil & $0.13 \mathrm{c}$ & $0.13 \mathrm{c}$ & $0.13 \mathrm{c}$ & $6.41 \mathrm{~d}$ \\
Biochar & $0.52 \mathrm{a}$ & $0.36 \mathrm{a}$ & $1.49 \mathrm{a}$ & $8.86 \mathrm{a}$ \\
$1 \mathrm{~T}+2 \mathrm{~B}$ & $0.28 \mathrm{~b}$ & $0.13 \mathrm{~b}$ & $0.67 \mathrm{~b}$ & $7.90 \mathrm{~b}$ \\
$2 \mathrm{~T}+1 \mathrm{~B}$ & $0.27 \mathrm{~b}$ & $0.13 \mathrm{~b}$ & $0.24 \mathrm{c}$ & $7.63 \mathrm{c}$ \\
\hline Lsd $(5 \%)$ & 0.25 & 0.21 & 0.22 & 0.06 \\
\hline
\end{tabular}

\subsection{Temperature of Media}

Temperatures in the media were similar over the 10-week period under the lath house. The temperature recorded was between $23.0^{\circ} \mathrm{C}$ and $34.0^{\circ} \mathrm{C}$, which was higher in the $9^{\text {th }}$ and lower in the $2^{\text {nd }}$ week. Further temperature increased up to the $8^{\text {th }}$ week across the media (Tab. 2).

Tab. 2 The mean temperatures recorded for the various media from week 1 to week 10.

\begin{tabular}{lllllllllll}
\hline Media & Week 1 & Week 2 & Week 3 & Week 4 & Week & Week & Week & Week & Week & Week \\
& & & & & 5 & 6 & 7 & 8 & 9 & 10 \\
\hline Topsoil & 25.3 & 26 & 28 & 30.4 & 29 & 30 & 31 & 33 & 34.2 & 29.9 \\
Biochar & 23.2 & 23 & 24 & 26.7 & 27 & 28 & 29 & 29 & 30.6 & 27.3 \\
1T+2B & 24.1 & 24 & 25.1 & 27.3 & 26 & 29 & 28 & 31 & 32.5 & 28.1 \\
2T+1B & 24.6 & 24 & 27 & 28.3 & 26 & 29 & 29 & 32 & 33 & 28.6 \\
\hline
\end{tabular}

\subsection{Relative Humidity}

The relative humidity within the media ranged from 84.0 to $95.0 \%$. There were fluctuations in the relative humidity within the poly-propagator over time. High relative humidity of $95.0 \%$ was recorded in the 6th week while the minimum relative humidity was recorded in the 4th week (Tab. 3).

Tab.3 The ambient temperature over the 10 week period.

\begin{tabular}{lllllllllll}
\hline WEEKS & Week & Week & Week & Week & Week & Week & Week & Week & Week & Week \\
& 1 & 2 & 3 & 4 & 5 & 6 & 7 & 8 & 9 & 10 \\
RH & 86 & 84 & 89 & 82 & 90 & 95 & 84 & 89 & 90 & 92 \\
\hline
\end{tabular}

\subsection{Effect of media on number of days to sprouting and number of leaves of Ixora coccinea propagules}

The different media formulations did not significantly affect the number of days to sprouting, survived cuttings, rooted cuttings and the root length $(\mathrm{cm})$ of the propagules. There were significant differences in the numbers of leaves recorded for each media treatment except at the $4^{\text {th }}$ and $6^{\text {th }}$ week after planting (Tab. 4). In the subsequent weeks, leaf production in Ixora coccinea for the various media showed significant differences. In the $8^{\text {th }}$ week, significantly higher number of leaves were recorded in topsoil and the mixture of topsoil and biochar (1:2) with values of 8.33 and 7.00 respectively whiles the least was recorded in the mixture of topsoil and biochar (2:1). At the $10^{\text {th }}$ week, significantly high number of leaves were recorded in topsoil only followed by the mixture of topsoil and biochar $(1: 2)$ and the mixture of topsoil and biochar (2:1). 
H. V. Adzraku et al.

Tab. 4 The effects of the propagating media on the number of leaves for Ixora coccinea at 4, 6, 8-and10 weeks after planting (WAP).

\begin{tabular}{lllll}
\hline Treatments & $4 \mathrm{WAP}$ & $6 \mathrm{WAP}$ & $8 \mathrm{WAP}$ & $10 \mathrm{WAP}$ \\
\hline Topsoil & $4.00 \mathrm{a}$ & $6.33 \mathrm{a}$ & $8.33 \mathrm{a}$ & $15.00 \mathrm{a}$ \\
Biochar & $0.00 \mathrm{~b}$ & $0.00 \mathrm{~b}$ & $0.00 \mathrm{~b}$ & $0.00 \mathrm{~b}$ \\
$1 \mathrm{~T}+2 \mathrm{~B}$ & $3.33 \mathrm{a}$ & $3.00 \mathrm{a}$ & $7.00 \mathrm{a}$ & $7.00 \mathrm{ab}$ \\
$2 \mathrm{~T}+1 \mathrm{~B}$ & $1.33 \mathrm{a}$ & $3.33 \mathrm{a}$ & $2.66 \mathrm{ab}$ & $8.66 \mathrm{ab}$ \\
\hline L.S.D $(5 \%)$ & 4.96 & 7.75 & 6.38 & 14.50 \\
\hline
\end{tabular}

\subsection{Effects of the propagating media on the number of roots for Ixora coccinea at 4, 6, 8, and 10 weeks after planting (WAP)}

There were no significant differences seen in the number of roots at the fourth, eighth and tenth week but in the sixth week significantly high number of root was recorded in topsoil and the mixture of topsoil and biochar (1:2) (16.66), In the $4^{\text {th }}$ week, one part of topsoil to two part of biochar recording (6.00) and two parts of topsoil to one part of biochar recording (5.33). (Tab. 5)

Tab. 5 Effects of the propagating media on the number of roots for Ixora coccinea at 4, 6, 8, and 10 weeks after planting (WAP).

\begin{tabular}{lllll}
\hline Media & 4WAP & $6 \mathrm{WAP}$ & $8 \mathrm{WAP}$ & $10 \mathrm{WAP}$ \\
\hline Topsoil & $7.33 \mathrm{a}$ & $16.66 \mathrm{a}$ & $32.33 \mathrm{a}$ & $38.33 \mathrm{a}$ \\
Biochar & $0.00 \mathrm{~b}$ & $0.00 \mathrm{~b}$ & $0.00 \mathrm{~b}$ & $0.00 \mathrm{~b}$ \\
1T+2B & $6.00 \mathrm{a}$ & $14.33 \mathrm{a}$ & $19.00 \mathrm{a}$ & $27.00 \mathrm{a}$ \\
2T+1B & $5.33 \mathrm{a}$ & $11.33 \mathrm{ab}$ & $26.33 \mathrm{a}$ & $31.33 \mathrm{a}$ \\
\hline LSD $(5 \%)$ & 5.28 & 11.90 & 16.41 & 15.29 \\
\hline
\end{tabular}

\subsection{Effects of the propagating media on the root length for Ixora coccinea at 4, 6, 8, and 10 weeks after planting (WAP)}

For root length topsoil had significantly the longest root followed by one part of topsoil to one part biochar 1T+2B and two parts of topsoil to one part biochar. Cuttings planted in topsoil only recorded $1.66 \mathrm{~cm}, 1.20 \mathrm{~cm}$ for the mixture of topsoil and biochar (1:2) and the mixture of topsoil and biochar (2:1) was $0.93 \mathrm{~cm}$. In the fourth week significantly longest roots were recorded in topsoil only and the shortest roots was recoreded by biochar. There were no significant difference in root length for the 6th week, 8th week and the 10th week (Tab. 6)

Tab. 6 Effects of the propagating media on the root length for Ixora coccinea at 4, 6, 8, and 10 weeks after planting (WAP).

\begin{tabular}{lllll}
\hline Treatment & $4 \mathrm{WAP}$ & $6 \mathrm{WAP}$ & $8 \mathrm{WAP}$ & $10 \mathrm{WAP}$ \\
\hline Biocahar & $0.00 \mathrm{~b}$ & $0.00 \mathrm{~b}$ & $0.00 \mathrm{~b}$ & $0.00 \mathrm{~b}$ \\
Topsoil & $1.66 \mathrm{a}$ & $8.53 \mathrm{a}$ & $9.96 \mathrm{a}$ & $10.00 \mathrm{a}$ \\
$1 \mathrm{~T}+2 \mathrm{~B}$ & $1.20 \mathrm{ab}$ & $9.06 \mathrm{a}$ & $11.60 \mathrm{a}$ & $12.00 \mathrm{a}$ \\
$2 \mathrm{~T}+1 \mathrm{~B}$ & $0.93 \mathrm{ab}$ & $9.96 \mathrm{a}$ & $9.66 \mathrm{a}$ & $10.00 \mathrm{a}$ \\
\hline LSD $(5 \%)$ & 1.35 & 2.37 & 8.26 & 7.68 \\
\hline
\end{tabular}

\subsection{Effect of media on number of leaves of Ficus pumila Propagules}

The different media did not significantly affect the number of leaves at the $8^{\text {th }}$ and $10^{\text {th }}$ week for rooting in Ficus pumila but were significance in the $2^{\text {nd }}$ and $4^{\text {th }}$ week. In the $2^{\text {nd }}$ week $1 \mathrm{~T}+2 \mathrm{~B}$ recorded significantly highest number of leaves (6.33) and least recorded in topsoil (1.66). Also, at the $4^{\text {th }}$ week significantly highest number of leaves were recorded by the mixture of topsoil and biochar (1:2) and the least in topsoil (Tab.7). 


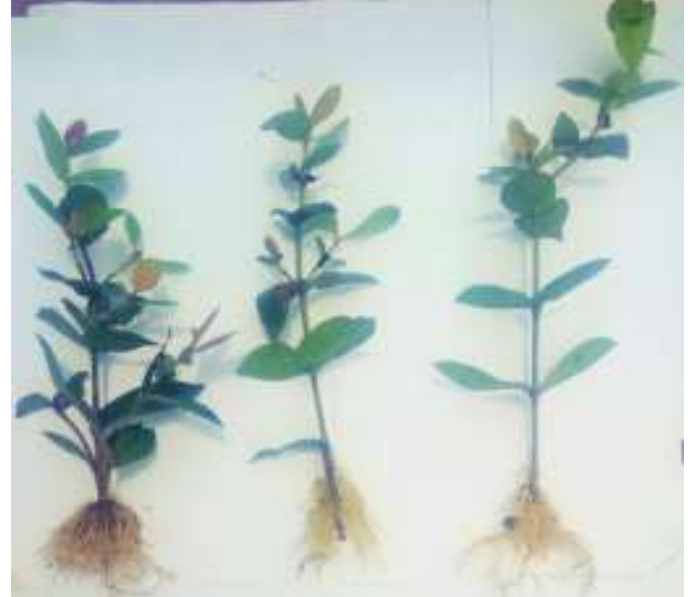

Fig. 1 Leaf and root development of Ixora coccinea in topsoil only.

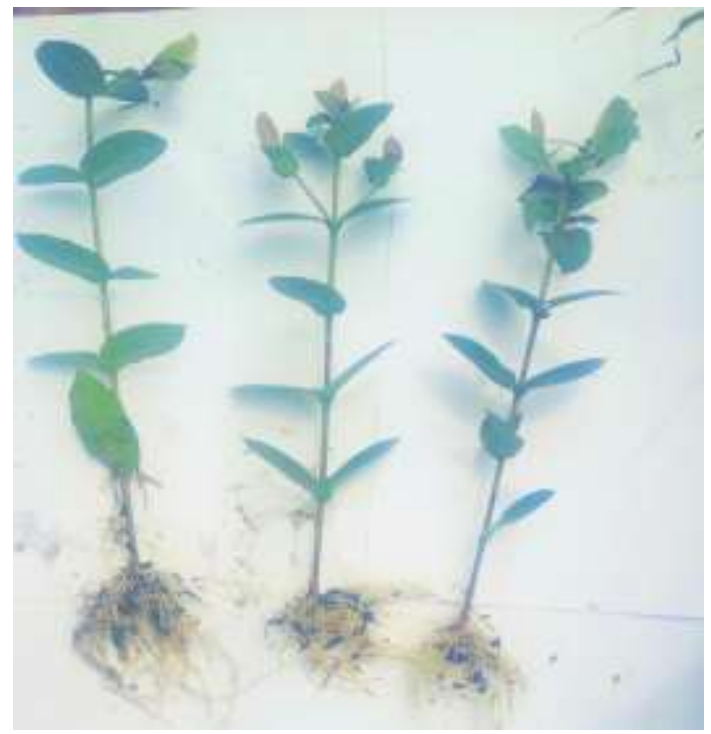

Fig. 3 Leaf and root development for Ixora coccinea in $1 \mathrm{~T}+2 \mathrm{~B}$.

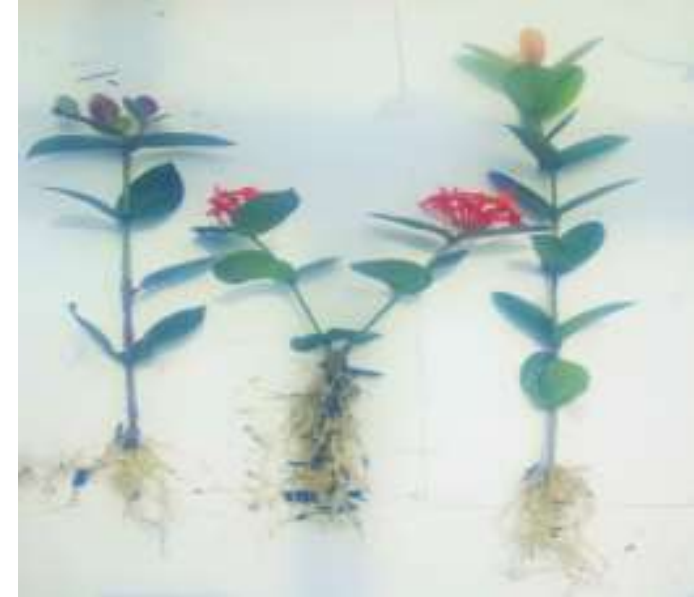

Fig. 2 Leaf and root development of Ixora coccinea in $2 \mathrm{~T}+1 \mathrm{~B}$.

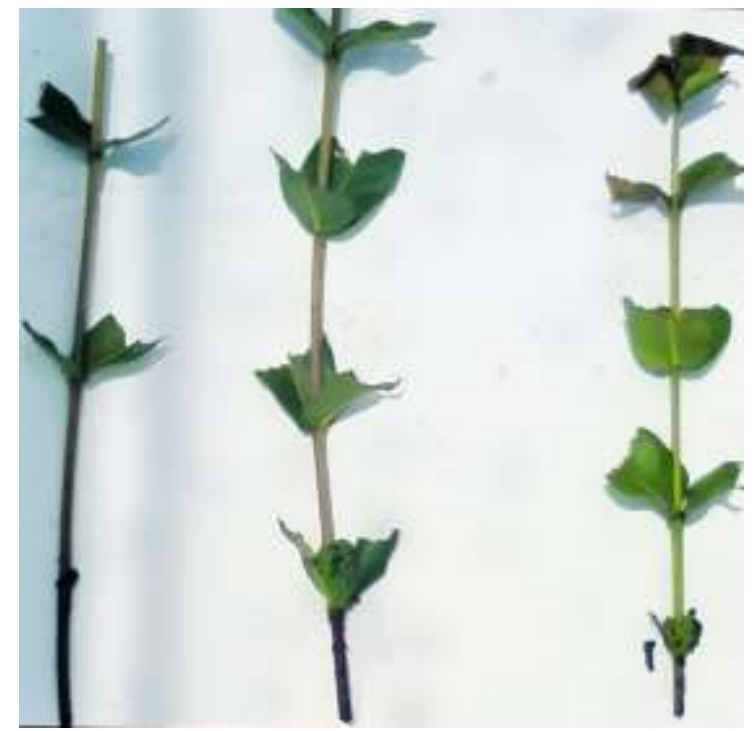

Fig. 4 No leaf and root development in biochar.

Tab. 7 Effects of the propagating media on the number of leaves of Ficus pumila at 4, 6, 8, and 10 weeks after planting (WAP).

\begin{tabular}{llllll}
\hline Treatment & $2 \mathrm{WAP}$ & $4 \mathrm{WAP}$ & $6 \mathrm{WAP}$ & $8 \mathrm{WAP}$ & $10 \mathrm{WAP}$ \\
\hline Topsoil & $1.66 \mathrm{~b}$ & $2.00 \mathrm{~b}$ & $8.00 \mathrm{a}$ & $5.66 \mathrm{a}$ & $7.00 \mathrm{a}$ \\
Biochar & $5.66 \mathrm{ab}$ & $7.33 \mathrm{ab}$ & $3.00 \mathrm{a}$ & $9.33 \mathrm{a}$ & $19.00 \mathrm{a}$ \\
$1 \mathrm{~T}+2 \mathrm{~B}$ & $6.33 \mathrm{a}$ & $12.00 \mathrm{a}$ & $12.00 \mathrm{a}$ & $19.00 \mathrm{a}$ & $21.33 \mathrm{a}$ \\
$2 \mathrm{~T}+1 \mathrm{~B}$ & $4.00 \mathrm{ab}$ & $6.00 \mathrm{ab}$ & $12.00 \mathrm{a}$ & $17.66 \mathrm{a}$ & $11,33 \mathrm{a}$ \\
\hline LSD $(5 \%)$ & 4.39 & 7.02 & 14.46 & 17.02 & 17.45 \\
\hline
\end{tabular}

\subsection{Effect of media on number of roots of Ficus pumila Propagules}

In terms of number of roots, the results show no significance in the 2nd, 4th, 6th and 10th week period. Nevertheless, on the 8th week, significantly, high number of roots was recorded in biochar only with a value of (15.00) and the least recorded in topsoil only with a value of (1.66). With biochar recording 9 times significantly more number of roots than topsoil (Tab. 8). 
Tab. 8 Effects of the propagating media on the number of roots for Ficus pumila at 4, 6, 8, and 10 weeks after planting (WAP).

\begin{tabular}{llllll}
\hline Treatments & $2 \mathrm{WAP}$ & $4 \mathrm{WAP}$ & $6 \mathrm{WAP}$ & $8 \mathrm{WAP}$ & $10 \mathrm{WAP}$ \\
\hline Topsoil & $0.66 \mathrm{a}$ & $2.33 \mathrm{a}$ & $11.66 \mathrm{a}$ & $1.66 \mathrm{~b}$ & $11.00 \mathrm{a}$ \\
Biochar & $3.66 \mathrm{a}$ & $6.33 \mathrm{a}$ & $2.66 \mathrm{a}$ & $15.00 \mathrm{a}$ & $9.33 \mathrm{a}$ \\
$1 \mathrm{~T}+2 \mathrm{~B}$ & $3.00 \mathrm{a}$ & $7.33 \mathrm{a}$ & $10.00 \mathrm{a}$ & $9.00 \mathrm{ab}$ & $12.66 \mathrm{a}$ \\
$2 \mathrm{~T}+1 \mathrm{~B}$ & $4.33 \mathrm{a}$ & $6.66 \mathrm{a}$ & $15.33 \mathrm{a}$ & $12.00 \mathrm{ab}$ & $9.00 \mathrm{a}$ \\
\hline LSD $(5 \%)$ & 4.74 & 10.81 & 18.38 & 10.51 & 21.22 \\
\hline
\end{tabular}

\subsection{Effect of media on of root length of Ficus pumila Propagules}

The different media did not have any significance on Ficus pumila on the roots length.

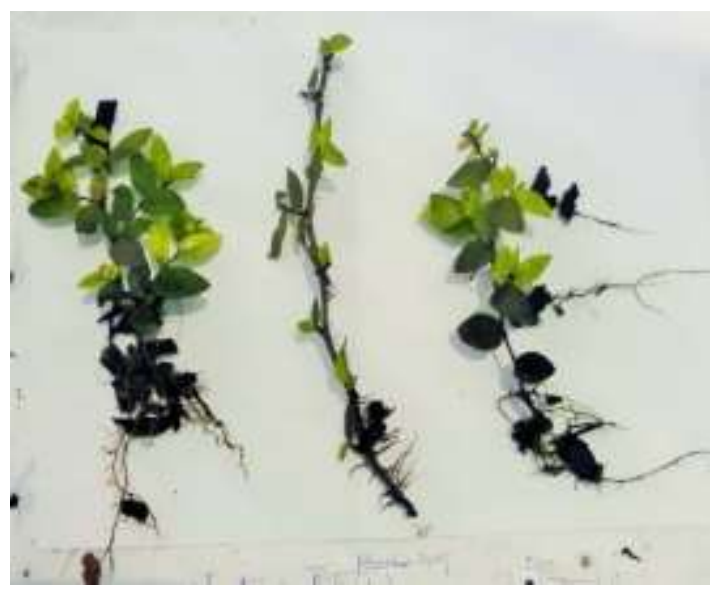

Fig. 4 Growth and development of

Ficus pumila cuttings in biochar.

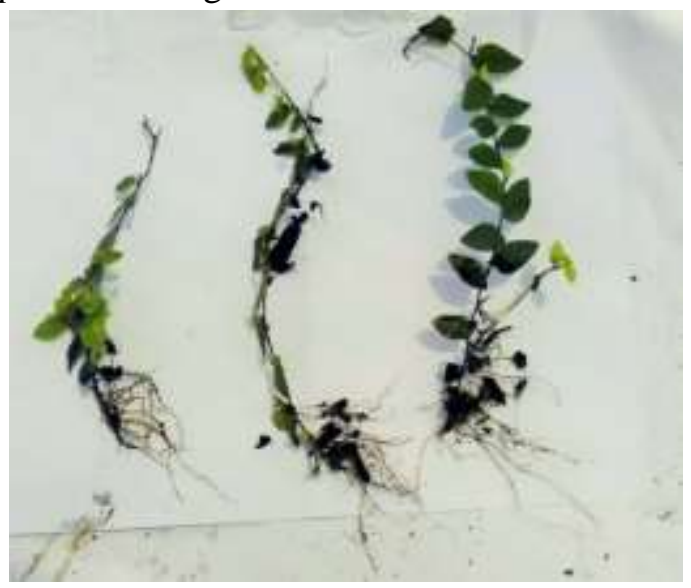

Fig. 7 Growth and development of

Ficus pumila cuttings in $1 \mathrm{~T}+2 \mathrm{~B}$.

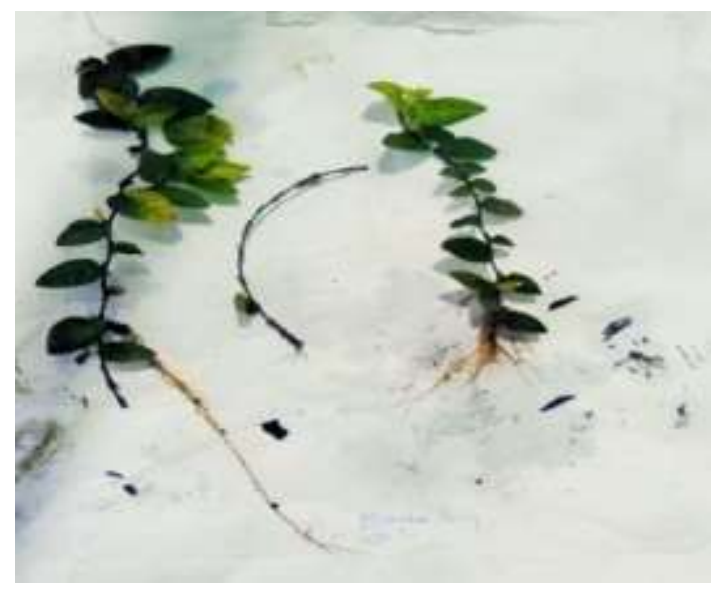

Fig. 6 Growth and development of Ficus pumila cutting in topsoil only.

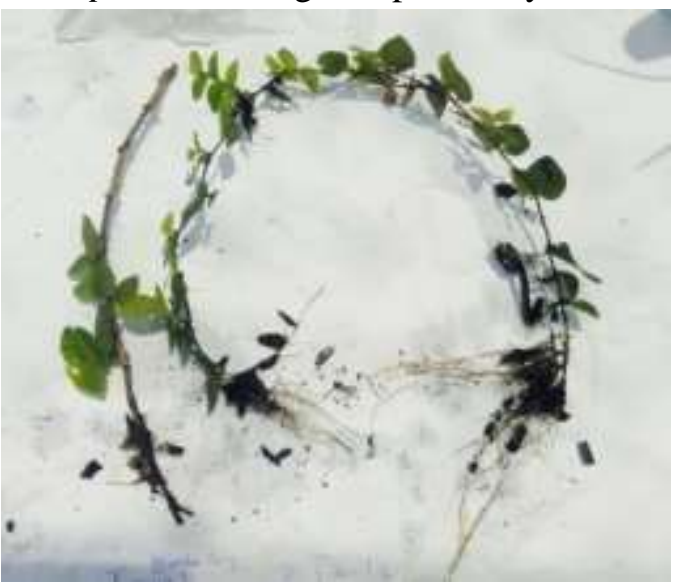

Fig. 8 Growth and development of Ficus pumila cuttings in $2 \mathrm{~T}+1 \mathrm{~B}$.

\section{Discussion}

\subsection{Physico-chemical properties of the media and their effect on the stock plants}

The significantly highest level of $\mathrm{N}$ in biochar used in the formulation of the various media could have accounted for the rapid vegetative growth of the cuttings. In the Ficus pumila cuttings there were vigorous leaf growths in the treatment containing biochar namely: $2 \mathrm{~T}+1 \mathrm{~B}$ and biochar only. The failure of the Ixora cuttings in the biochar to produce leaves could be due to high $\mathrm{C} / \mathrm{N}$ ratio of biochar and greater potential for $\mathrm{N}$ immobilization. Liang et al. (2006) opined that, some amount of 
decomposition occurs when fresh biochar is added to soils and this could induce net immobilization of inorganic $\mathrm{N}$ already present in the soil solution, thus leading to a reduction in the $\mathrm{N}$ content in the soil. This could better explain the reason why at 8WAP, some of the leaves of Ficus pumila in biochar turned yellowish to brown. Vigorous root formation was recorded in all the cuttings for the Ficus pumila especially in the biochar only treatment. Also, Ixora coccinea cuttings in topsoil had significantly highest number of roots formed in Topsoil only. This could be attributed to the high available phosphorus percentage recorded in all the media before the formulation of the media for propagation. This affirms findings by Nigussie et al. (2012) that phosphours was made available in the soil due to the presence of high $\mathrm{P}$ in the feedstock (sugarcane wastestock). The results of the current study indicated significantly high content of $\mathrm{K}$ in the biochar and least in Topsoil. Similarly, findings by Nigussie et al. (2012) and Lehmann et al. (2003) concluded that high concentrations of Biochar are likely to increase the soil K considerably and this can be beneficial in K deficient soils. Moreover, Ogundele et al. (2011) reported that low $\mathrm{K}$ content found in soil could be due to the low content of $\mathrm{K}$ in the trees that were used as feedstock for the Biochar production and subsequently used as a soil amendment. The $\mathrm{pH}$ values for the Topsoil and Biochar media were acidic and basic respectively. Leonard (2012) reported that the optimum $\mathrm{pH}$ for most plants is 5.5-7.0. Topsoil recorded significantly high number of leaves and roots on Ixora cuttings probably due to the fact that Ixora grows best in acidic media. The acidic nature of the topsoil enabled it to obtain more available nutrients for the plants as found by Handreck and Black (1999). Additionally, biochar media recorded significantly high number of leaves and roots in Ficus pumila and this could be due to the fact that biochar had high cation exchange capacity (CEC) which improved the ability of a media to hold and retain nutrients. By physical observation, biochar particles looked rough textured and porous than the topsoil. The combination of the two components in $1 \mathrm{~T}+2 \mathrm{~B}$ and $2 \mathrm{~T}+1 \mathrm{~B}$ made it more porous allowing excess water to drain from it with adequate oxygen penetration and this has been supported by (Hartmann et al. 2002). This could have accounted for the reason why biochar drained off excess water easily and faster compared to the topsoil. Topsoil obviously has few and small pore spaces. Under this condition, plant roots will have considerably low amount of air with lots of moisture in the topsoil. According to Hartmann et al. (2002), soil texture influences other properties of the soil such as the water-holding capacity and nutrient retention and utilization.

\subsection{Leaf and root production of ixora coccinea and Ficus pumila propagules}

Topsoil produced the greatest number of leaves in the 4th week as compared to the other treatments probably because its texture influenced low water holding capacity and considerable aeration around the base of the cutting which enhanced rooting. This could also be because of the acidic nature of the topsoil which in turn supplied more cations which enabled the media to hold larger supplies of nutrients for the stem cutting. This promoted early root growth and subsequent vegetative growth on the stem cuttings. The high temperatures in the transparent polythene media within the first 2 weeks also promoted shoot growth. Cuttings in Topsoil only had enough moisture to keep the stems from drying out. According to Handreck and Black (1999), Ixora coccinea thrives best in acidic soils. The acidic nature of the soilless media in turn supplied more cations such as $\mathrm{Ca} 2+$ and $\mathrm{Mg} 2+$ which then improved the availability of other nutrients and helped the media to hold larger supplies of nutrients for plants. Ixora stem cuttings planted in Biochar only did not thrive well and so died out probably due to the large pore spaces in the media, which resulted in much drainage and high amount of aeration. Early sprouting in Ficus pumila was observed in the $2^{\text {nd }}$ week. $2 \mathrm{~T}+1 \mathrm{~B}$ had more number of leaves than the other media treatments in Ficus pumila. Temperatures over the media during the first two weeks initiated sprouting ahead of rooting. However, high media temperatures also accounted for early root growth and utilization of nutrient. Lopez and Runkle (2008), observed that maintaining air temperature 
lower than medium temperature retards shoot growth and promotes root development. Furthermore, Hartmann et al. (2002), indicated that root initiation in cuttings is temperature driven but subsequent root growth is strongly dependent on stored food in the stem cuttings. In the 8th week of propagation, the cuttings in the treatments containing biochar started showing yellowish green colour and this could be attributed to nitrogen deficiency in the media.

\section{References}

Caron J, and Rochefort L (2013) Use of peat in growing media: state of the art on industrial and 102 scientific effort envisioning sustainability. Acta Hort. 982:15-22.

Chan KY, Xu Z (2009) Biochar: Nutrient Properties and Their Enhancement. Biochar for environmental management: science and technology, 1, 67-84.

Cheng CH, Lehmann J, Thies JE, Burton SD, Engelhard, MH (2008) Oxidation of black carbon by biotic and abiotic processes. Org. Geochem., 37: 1477-1488.

Dumroese RK, Heiskanen J, Englund K, Tervahauta A (2011) Pelleted biochar: 138 Chemical and physical properties show potential use as a substrate in container nurseries. 139 Biomass and Bioenerg. 35(5):2018-2027.

Handreck K, Black N (1999) Growing Media for Ornamental Plants and Turf, University of South Wales Press, pp 111-129.

Hartmann HT, Kester DE Jr, Davies FT, Geneve RL (2002) Plant Propagation, Principles and Practices, 7th Edition, Prentice Hall, Upper Saddle River, New Jersey. P 880.

http://www.independent.co.uk/environment/climate-change/ancient-skills-couldreverse- globalwarming-1055700.html. Accessed on 19th December, 2016.

Idun IA, Kumah P, Adzraku HV (2011) Rooting and vegetative growth responses of difficult-to-root Ixora coccinea and Ficus benjamina cv. starlight to different stem cutting types and soilless media. African Journal of Plant Science, 5(13), 773-780.

Ioannidou O, Zabaniotou A (2007) Agricultural residues as precursors for activated carbon production - a review. Renewable and Sustainable Energy Reviews, 11(9), 1966-2005.

Lean G (2008) "Ancient Skills 'Could Reverse Global Warming'", The Independent, http://www.independent.co.uk/environment/climate-change/ancient-skills-couldreverseglobalwarming-1055700.html. [Accessed: 19th October, 2016].

Lehmann J, da Silva JP, Steiner C, Nehls T, Zech W, Glaser B (2003) Nutrient availability and leaching in an archaeological anthrosol and a ferralsol of the central amazon basin: Fertilizer, manure and charcoal amendments. Plant Soil 2003, 249, 343-357.

Leonard P (2012) pH for the garden, University of Vermont Extension Department of Plant and Soil Science website, accessed on 8th May, 2017

Liang B, Lehmann J, Solomon D, Kinyangi J, Grossman J, O’Neill B, Skjemstad JO, Thies J, Luizao FJ, Petersen J, Neves EG (2006) Black Carbon Increases Cation Exchange Capacity in Soils, Soil Science Society of America Journal 70:1719-1730.

Lopez RG, Runkle ES (2008) Photosynthetic daily light integral during propagation influences rooting and growth of cuttings and subsequent development of New Guinea impatiens and petunia. HortScience, 43(7), 2052-2059.

Nigussie A, Kissi E, Misganaw M, Ambaw G (2012) Effect of Biochar Application on Soil Properties and Nutrient Uptake of Lettuces (Lactuca sativa) Grown in Chromium Polluted Soils, AmericanEurasian. Journal of Agricultural and Environmental Science 12 (3): 369-376, 2012, ISSN 18186769, IDOSI Publications.

Northup JI (2013) Biochar as a replacement for perlite in greenhouse soilless substrates. Iowa 276 State Univ. Ames, IA, M.S. Thesis. 65-13399.

Ogundele AT, Eludoyin OS, Oladapo OS (2011) Assessment of Impacts of Charcoal Production on Soil Properties in the Derived Savanna, Oyo state, Nigeria. Journal of Soil Science and Environmental Management 2: 142-146.

Reddy KR, Xie T, Dastgheibi S (2014) Evaluation of biochar as a potential filter media for the removal of mixed contaminants from urban storm water runoff. Journal of Environmental Engineering, 140(12), 04014043. 
H. V. Adzraku et al.

Steiner C, Harttung T (2014) Biochar as growing media additive and peat substitute. Solid 322 Earth Discussions, 6(1):1023-1035.

Van Zweiten L, Kimber S, Downie A, Morris S, Petty S, Rust J, Chan KY (2010) A glasshouse study on the interaction of low mineral as biochar with nitrogen In A Sandy Soil. Australian Journal of Soil Research 48, 569-576.

Yanai Y, Toyota K, Okazaki M (2007) Effects of charcoal addition on $\mathrm{N}_{2} \mathrm{O}$ emission from soil from rewetting air-dried soil in short-term laboratory experiments. Soil Sci Plant Nutr 53:181-188. 